\section{Synthesis of Centrohexacyclic Hydrocarbons by the Propellane Route: Centrohexaindan and Tribenzocentrohexaquinane**}

\section{Dietmar Kuck, * Bernd Paisdor, and Detlef Gestmann}

Dedicated to Dr. Howard E. Simmons, Jr. on the occasion of his 65 th birthday

The construction of centrohexacyclic hydrocarbon frameworks with the general structure 1 (centrohexacyclanes; ${ }^{[1]}$ Scheme 1) continues to present a challenge in organic polycycle chemistry. In these types of structures six annelated carbocycles share a central neopentane unit of five quaternary carbon atoms and form a microlattice with nonplanar topology. ${ }^{[2]}$ The compounds with six centrally annelated cyclopentane rings should be relatively strain-free. ${ }^{[1.3]}$ Thus relatively undistorted frameworks of, for example, perhydrotriquinacene and all-cis-[5.5.5.5]fenestrane can be found in the yet unknown parent structure, centrohexaquinane 2 , which can be considered to be the condensation center of four pentagon dodecahedrane units. ${ }^{[1]}$ Nevertheless, synthetic routes to 2 and centrohexaquinacene 3 , which was first
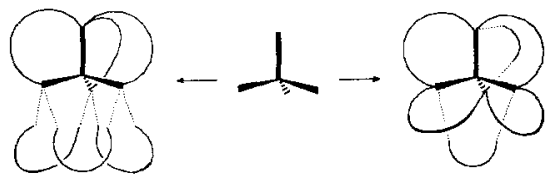

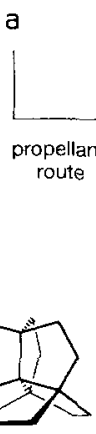

2

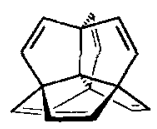

3

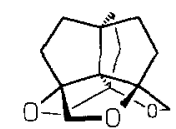

4
Scheme 1

proposed in $1978{ }^{[4]}$ must take into account considerable steric compression and/or fragmentation between the components that are to be joined. Therefore, not surprisingly, centrohexacyclic hydrocarbons ${ }^{[5,6]}$ and the corresponding heterocycles ${ }^{[7-9]}$ have remained quite rare. Only one directed synthesis of a centrohexacyclic hydrocarbon framework was reported previously, namely the synthesis of the sixfold benzoannelated derivative of 2 , centrohexaindan 9. ${ }^{[5]}$ We have now discovered a new route to 9 and centrohexacyclic triethers related to the "SimmonsPaquette molecule" $4^{[8,9]}$ and have developed a synthesis of the novel tribenzocentrohexaquinanes.

In our first synthesis of 9 the already highly condensed fenestrindan 7, which is thus protected against fragmentation, was

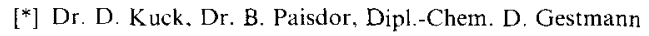

Fakultät für Chemie der Universität

Universitätsstrasse 25. D-33615 Bielefeld (FRG)

Telefix: Int. code $+(521) 106-6146$

[**] Benzoinnelated Centropolyquinanes, Part 18. This work was supported by the Deutsche Forschungsgemeinschaft. - Part 17: [7b]. bridged twice (route b to 1 in Scheme 1 and route $5 \rightarrow 7 \rightarrow 9$ in Scheme 2). A newer alternative synthesis, the propellane route, starts with 9,10,11-triptindantrione $6,{ }^{[10]}$ a [3.3.3]propellane accessible from 1,3-indandione 5 in only four steps (route a to 1 in Scheme 1 and route $5 \rightarrow 6 \rightarrow 8 \rightarrow 9$ in Scheme 2).

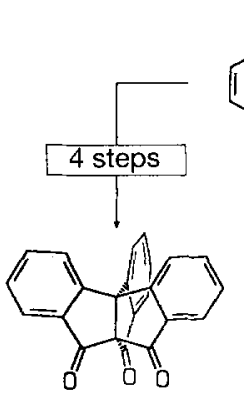

6

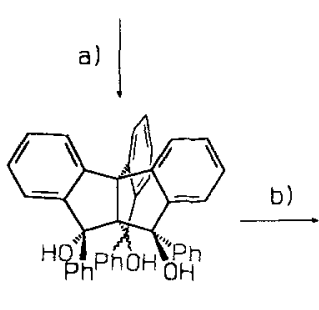

B

)

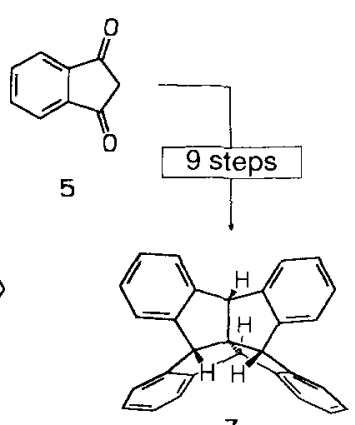

7
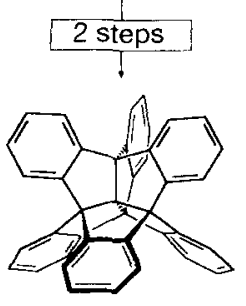

9
Scheme 2. Synthesis of centrohexaindan 9 by the propellane route and by the fenestrane route. $5 \rightarrow 6:$ ref. [10]: $5 \rightarrow 9:$ ref. [5]. a) $\mathrm{PhLi}(20 \mathrm{~mol})$ in benzene $/ \mathrm{Et}_{2} \mathrm{O}$ $\left(-\mathrm{C}_{6} \mathrm{H}_{12} ; \mathrm{H}_{2} \mathrm{O}\right.$; b) $\mathrm{H}_{3} \mathrm{PO}_{4} /$ xylene, $\Delta$; yield $40 \%$ of 6

Three equivalents of aliphatic Grignard compounds like $\mathrm{CH}_{3} \mathrm{MgBr}$ and $\mathrm{C}_{6} \mathrm{H}_{5} \mathrm{CH}_{2} \mathrm{MgBr}$ can be added to triptindantrione 6 with remarkable ease and without ring opening. Only two equivalents of phenylmagnesium bromide react with $6 ;{ }^{[10]}$ however, threefold addition is possible if phenyllithium is employed in a poorly solvating medium. After hydrolysis a mixture of isomeric triols $\mathbf{8}$ is obtained, which can be cyclodehydrated with acid catalysis to give 9. These two steps, in which a total of six $\mathrm{C}-\mathrm{C}$ bonds are formed, conclude the synthesis of centrohexaindan 9 from 5 in only six steps and with a total yield of up to $24 \% .^{[1]}$

The propellane route was then used for the first construction of centrohexaquinanes with partial benzoannelation. The synthesis of tribenzocentrohexaquinane 14 is shown in Scheme 3. In this synthesis a $\mathrm{C}_{2}$ synthon was required which, in analogy to the sequence $6 \rightarrow 8 \rightarrow 9$, would undergo threefold nucleophilic addition to $\mathbf{6}$ and subsequent cyclization to yield the triquinacene framework complementary to the [3.3.3]propeliane unit. Neither the application of the strategies used by Simmons III and Maggio, ${ }^{[8]}$ and by Paquette et al. ${ }^{[9]}$ (e.g. rearrangement of a trispiro[[3.3.3]propellanetris(oxirane)] to 4) to the triptindan system nor other approaches of our own were successful. ${ }^{[10,12,13]}$ A surprisingly direct route to 14 and interesting derivatives is based on the threefold reaction of 6 with lithium acetylides.

Unexpectedly, the reaction of triptindantrione 6 with three equivalents of lithium acetylide in THF furnishes not triol $\mathbf{1 0}$ $(\mathrm{R}=\mathrm{H})$ but tris(enol ether) $11 \mathrm{a}$, the first derivative of the "Simmons-Paquette molecule" 4. The excessive steric bulk of the neopentane core of the triptindan framework apparently favors the nucleophilic addition of the intermediate alcoholate to the syn-1,3-ethynyl group. ${ }^{[1]}$ The intramolecular additions can be completed by treating the reaction mixture with aqueous sodi- 


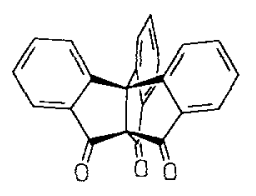

6

b)

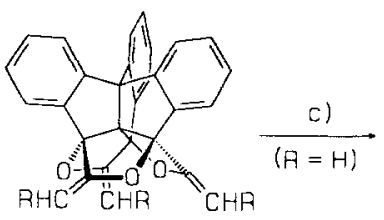

11a $(\mathrm{R}=\mathrm{H})$

$110 \quad(F=P r)$

d)

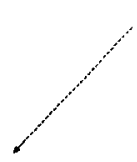

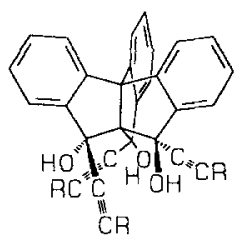

10 $(\mathrm{F}=n \mathrm{Bu})$

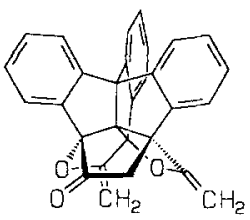

12

14

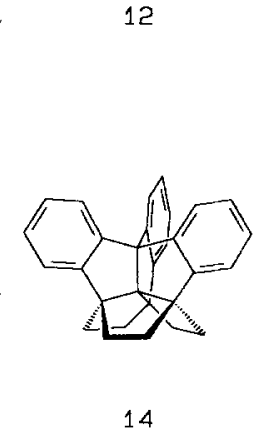

$13 a \quad(\mathrm{P}=\mathrm{H})$
$13 \mathrm{~b} \quad(\mathrm{R}=\mathrm{Ph})$

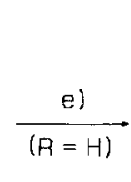

Scheme 3. a) $n \mathrm{BuCCH} / n \mathrm{BuLi}, \mathrm{THF}, 20^{\circ} \mathrm{C}$, then $\mathrm{H}_{2} \mathrm{O}, \mathrm{Na}_{2} \mathrm{CO}_{3}$; b) $\mathrm{C}_{2} \mathrm{H}_{2}$ of $\mathrm{PhCCH} / n \mathrm{BuLi}$, THF, $T=-80^{\circ} \mathrm{C} \rightarrow 20 \mathrm{C}$ or $\mathrm{T}=20^{\circ} \mathrm{C}$, respectively, then $\mathrm{H}_{2} \mathrm{O}$. $\mathrm{Na}_{2} \mathrm{CO}_{3} ;$ c) decalin, $300 \mathrm{C}, 4 \mathrm{~h}$; d) decalin, $\left.300 \circ \mathrm{C}, 24 \mathrm{~h} ; \mathrm{e}\right) \mathrm{N}_{2} \mathrm{H}_{4} \cdot \mathrm{H}_{2} \mathrm{O}$, diethylene glycol, $\mathrm{KOH}, T=140 \rightarrow 210 \mathrm{C}$.

um carbonate; unfortunately, the yield of $\mathbf{1 1}$ a is only $25 \%$. The analogous reaction with phenylacetylene provides $\mathbf{1 1} \mathbf{b}$ in $27 \%$ yield, but so far the reaction with 1-hexyne has only given triol $10(\mathrm{R}=n \mathrm{Bu})$.

Tris(enol ether)s 11 are characterized by mass spectrometry and IR and NMR spectroscopy (Table 1). The high molecular symmetry is reflected in the simple ${ }^{1} \mathrm{H}$ and ${ }^{13} \mathrm{C}$ NMR spectra; the $\mathrm{AB}$ pattern of the signals for the olefinic methylene protons of $11 \mathrm{a}\left({ }^{2} J=2.8 \mathrm{~Hz}\right)$ is particularly characteristic. In the mass spectra of the enol ethers the elimination of up to three equivalents of $\mathrm{CO}$ is evident in the upper mass range. This indicates that heterocycles $11 \mathrm{a}$ and $11 \mathrm{~b}$ rearrange to the corresponding carbocycles $13 \mathrm{a}$ and $13 \mathrm{~b}$ not only in the mass spectrometer, but possibly also on the preparative scale. Whereas attempts with Brønsted and Lewis acids $\left(\mathrm{H}_{2} \mathrm{SO}_{4} / \mathrm{H}_{2} \mathrm{O} / \mathrm{THF}, \mathrm{AlBr} / \mathrm{CH}_{2} \mathrm{Cl}_{2}\right)$ and with $\mathrm{LiCl}_{4} /$ ether $^{[15]}$ were not successful, the thermolysis ${ }^{[16]}$ of $11 \mathbf{a}$ in decalin at $300^{\circ} \mathrm{C}$ provided the desired trione $13 \mathbf{a}$ in $30 \% ; 11$ b was converted diastereoselectively into the triphenyl derivative $13 \mathbf{b}$ in even $60 \%$ yield. ${ }^{[17]}$ As expected, the mass spectra of the two triones are very similar to those of compounds 11, but features typical of cyclopentanone rings are observed in the ${ }^{1} \mathrm{H}$ and ${ }^{13} \mathrm{C}$ NMR, and IR spectra, for example an AB spectrum with ${ }^{2} J=-19.6 \mathrm{~Hz}(13 \mathrm{a})$. Thermolysis of $11 \mathrm{a}$ for shorter periods resulted in the product of a single rearrangement, monoketone 12. The parent compound of the new centrohexacycles, tribenzohexaquinane 14, was obtained by WolffKishner reduction of $\mathbf{1 3} \mathbf{a}$ and also characterized unequivocally (Table 1)

We are currently trying to convert centrohexaquinanetrione $\mathbf{1 3}$ into the corresponding (unsaturated) tribenzocentrohexaquinacenes. These types of triquinanetriones and triquinacenes, which
Table 1. Physical and spectroscopic data for compounds 11, 13, and 14

11 a: Colorless crystals. m.p. $>360^{\circ} \mathrm{C} ;{ }^{1} \mathrm{HNMR}\left(300 \mathrm{MHz}, \mathrm{CDCl}_{3}, \mathrm{TMS}\right): \delta=$ 4.61, 4.67 (AB spectrum, $\left.{ }^{2} J=2.8 \mathrm{~Hz}, 6 \mathrm{H}\right), 7.38(\mathrm{~m}, 6 \mathrm{H}), 7.54(\mathrm{~d}, 3 \mathrm{H}), 7.78(\mathrm{~d}$, $3 \mathrm{H}): \operatorname{IR}(\mathrm{KBr}): \tilde{r}=1656 \mathrm{~cm}^{-1}(\mathrm{C}=\mathrm{C}) ; \mathrm{MS}($ EI. $70 \mathrm{eV}): m_{-2}: 414\left(M^{+*}, 36\right), 386$ (36). $358(42), 330(100)$ : HRMS: $\left(\mathrm{C}_{29} \mathrm{H}_{18} \mathrm{O}_{3}\right)$ calcd 414.1256 ; found 414.1265 11 b: Colorless crystals. m.p. $272{ }^{\circ} \mathrm{C}$; 'H NMR (300 MHz, CDCl. TMS): $\delta=5.97$ (s. $3 \mathrm{H}), 7.14(\mathrm{t}, 3 \mathrm{H}), 7.30(\mathrm{t}, 6 \mathrm{H}), 7.41(\mathrm{~m}, 6 \mathrm{H}), 7.66(\mathrm{~d}, 6 \mathrm{H}), 7.74(\mathrm{~m}, 3 \mathrm{H}) .7 .80$ (m. $3 \mathrm{H}): \operatorname{IR}(\mathrm{KBr}): \hat{i}=1671 \mathrm{~cm}^{-1}(\mathrm{C}=\mathrm{C})$ : MS $(\mathrm{El} .70 \mathrm{eV}): m=: 642\left(\mathrm{M}^{+\cdot} .100\right)$. $614(20), 586(35), 558(16)$; HRMS: $\left(\mathrm{C}_{4}, \mathrm{H}_{30} \mathrm{O}_{3}\right)$ calcd 642.2195; found 642.2186 13a: Colorless crystals, m.p. $>360 \mathrm{C} ;{ }^{3} \mathrm{H} \mathrm{NMR}\left(300 \mathrm{MHz}, \mathrm{CDCl}_{3}\right.$, TMS): $\delta=2.84 .3 .27\left(\mathrm{AB}\right.$ spectrum, $\left.\left.\right|^{2} J \mid=19.6 \mathrm{~Hz}, 6 \mathrm{H}\right) .7 .30(\mathrm{~m}, 9 \mathrm{H}) .7 .84(\mathrm{~d}, 3 \mathrm{H}):$ IR $(\mathrm{KBr}): \tilde{r}=1745 \mathrm{~cm}^{-1}(\mathrm{C}=\mathrm{O})$; MS (EI, $\left.70 \mathrm{eV}\right): n=: 414\left(M^{+} \cdot 49\right), 386(41), 358$ (39). $330(100)$; HRMS: $\left(\mathrm{C}_{29} \mathrm{H}_{18} \mathrm{O}_{3}\right)$ calcd 414.1256: found 414.1257

13b: Colorless crystals, m.p. $298^{\circ} \mathrm{C}$ : ${ }^{1} \mathrm{H}$ NMR $\left(300 \mathrm{MHz}, \mathrm{CDCl}_{3}, \mathrm{TMS}\right): \delta=4.74$ (s. $3 \mathrm{H}), 6.34\left(\mathrm{~d},{ }^{3} J=7.8 \mathrm{~Hz}, 3 \mathrm{H}\right), 6.50$ (br. d, ${ }^{3} J=7.0 \mathrm{~Hz}, 6 \mathrm{H}$ ). 6.90 (td, $\left.{ }^{3} J=7.5 \mathrm{~Hz},{ }^{4} J=0.8 \mathrm{~Hz}, 3 \mathrm{H}\right) .7 .05\left(\mathrm{t} .{ }^{3} J \approx 7.5 \mathrm{~Hz} .6 \mathrm{H}\right) .7 .14\left(\mathrm{~d},{ }^{3} J \approx 7.4 \mathrm{~Hz}, 3 \mathrm{H}\right)$, $7.27\left(\mathrm{td},{ }^{3} J=7.5 \mathrm{~Hz},{ }^{4} J=0.9 \mathrm{~Hz}, 3 \mathrm{H}\right), 7.82\left(\mathrm{~d},{ }^{3} J=7.8 \mathrm{~Hz}, 3 \mathrm{H}\right) ; \mathrm{IR}(\mathrm{KBr})$ : $\hat{v}=1741 \mathrm{~cm}^{-1}(C=\mathrm{O}) ; \operatorname{MS}($ EI. $70 \mathrm{eV}): m / z: 642\left(M^{+} \cdot 100\right), 614(53), 586(75) .558$ (32): HRMS: $\left(\mathrm{C}_{4}, \mathrm{H}_{30} \mathrm{O}_{3}\right)$ calcd 642.2195 ; found 642.2194

14: Colorless crystals. m.p. $264 \mathrm{C}:{ }^{1} \mathrm{H} N M R\left(250 \mathrm{MHz}_{2} \mathrm{CDCl}_{3}, \mathrm{TMS}\right): \delta=1.93$. 2.17 (AA'BB' spectrum. $12 \mathrm{H}) .7 .107 .25(\mathrm{~m}, 9 \mathrm{H}) .7 .67\left(\mathrm{~d}^{3} J=7.4 \mathrm{~Hz} .6 \mathrm{H}\right): \mathrm{MS}$ (EI, $70 \mathrm{eV}): m /=: 372\left(M^{+}, 100\right), 358(13), 343(15), 329(13), 316(15):{ }^{13} \mathrm{C}$ NMR $\left.\left.\left(62.9 \mathrm{MHz}, \mathrm{CDCl}_{3}, \mathrm{TMS}\right): \delta=39.83\left(\mathrm{t}_{1} \mathrm{CH}_{2}\right) .65 .88\left[\mathrm{~s}, \mathrm{C}(\mathrm{C})(\mathrm{Ar})\left(\mathrm{CH}_{2}\right)\right)_{2}\right)\right], 77.22[\mathrm{~s}$. $\left.\mathrm{C}(\mathrm{Ar})_{3}\right], 123.58(\mathrm{t}), 124.25(\mathrm{t}), 127.58(\mathrm{t}) .127 .63(\mathrm{t}), 148.36(\mathrm{~s}), 150.34(\mathrm{~s})$. the signal of the centro-C atom is missing; HRMS: $\left(\mathrm{C}_{24} \mathrm{H}_{24}\right)$ ealcd 372.1878 ; found 372.1879

have their convex molecular faces completely shielded, ${ }^{[18,19]}$ may be key intermediates in new, promising approaches to pentagon dodecahedranes from two triquinacene units. ${ }^{[18 \mathrm{c}, 18 \mathrm{~d}, 20-22]}$

In conclusion we note that the propellane route described here for the construction of centrohexacyclic hydrocarbons may serve as an example of how the a priori unfavorable steric relations mentioned at the beginning of this report may also be advantageous for such compact structures. The remarkably facile formation of tris(enol ether) $\mathbf{1 1}$ is apparently a result of a proximity effect, and the subsequent consecutive rearrangements do not provide any possibility for the fragmentation of the molecular framework. The next particularly challenging step is determining whether the new propellane route leading to benzoannelated centrohexaquinanes like $\mathbf{9}$ and $\mathbf{1 4}$ may also be useful in the synthesis of the parent compound, centrohexaquinane 2 .

\section{Experimental Procedure}

9: A suspension of $6(3.36 \mathrm{~g} .10 .0 \mathrm{mmol})$ in $250 \mathrm{~mL}$ of benzene was prepared with exclusion of air and moisture. A solution of phenyllithium $(2 \mathrm{M}, 100 \mathrm{~mL})$ in diethyl ether/cyclohexane was then added and the reaction mixture heated at $40^{\circ} \mathrm{C}$ for $12 \mathrm{~h}$. After hydrolysis the organic phase was dried and concentrated. and the biphenyl formed removed by Kugelrohr distillation. The remaining triol 8 was dissolved in $250 \mathrm{~mL}$ of xylene and treated with $5 \mathrm{~mL}$ of orthophosphoric acid, and the reaction mixture was heated for $24 \mathrm{~h}$ with a water separator. After the reaction mixture had cooled the organic layer was decanted off, dried over sodium sulfate, and concentrated. The brown residue was filtered over silica gel $\left(\mathrm{CHCl}_{3}\right)$ and recrystallized from dichloromethane/hexane. Pure 9 (MS. NMR [5]) was obtained as colorless needles $(2.07 \mathrm{~g}, 40 \%)$

$11 \mathrm{a}$ and $11 \mathrm{~b}$ : A suspension of $6(3.36 \mathrm{~g}, 10.0 \mathrm{mmol})$ in $200 \mathrm{~mL}$ of THF was added dropwise over $30 \mathrm{~min}$ to a solution of lithium acetylide [23] $(1.06 \mathrm{~g}, 33.0 \mathrm{mmol})$ in $200 \mathrm{~mL}$ of THF cooled at $-90^{\circ} \mathrm{C}$. The temperature was not allowed to exceed $-80^{\circ} \mathrm{C}$ during the addition. After the addition was complete, the red-brown solution was stirred for $60 \mathrm{~min}$ before it was allowed to warm to room temperature. Water $(80 \mathrm{~mL})$ and then solid $\mathrm{Na}_{2} \mathrm{CO}_{3}$ were added until the aqueous layer had a pulpy consistency. After a further $12 \mathrm{~h}$ of stirring, the organic layer was decanted off and the residue washed with $\mathrm{CHCl}_{3}(2 \times 200 \mathrm{~mL})$. The combined organic layers were dried with $\mathrm{Na}_{2} \mathrm{SO}_{4}$ and concentrated. Column chromatography on silica gel $\left(\mathrm{CHCl}_{3}\right.$ /hexane) provided 11 a $(1.04 \mathrm{~g}, 25 \%)$. - When lithium phenylacetylide $(3.57 \mathrm{~g}, 33.0 \mathrm{mmol})$ was used and the reaction conducted at room temperature, $11 \mathrm{~b}$ $(1.73 \mathrm{~g}, 27 \%)$ was obtained after analogous workup.

13a and 13b: A mixture of 11 a (200 mg, $480 \mu \mathrm{mol})$ or $11 \mathrm{~b}(200 \mathrm{mg}, 310 \mu \mathrm{mol}), 8 \mathrm{mg}$ of hydroquinone, and $10 \mathrm{~mL}$ of anhydrous decalin was sealed under nitrogen in a thick-walled glass ampule and heated at $300^{\circ} \mathrm{C}$ in an oven for $24 \mathrm{~h}$. After cooling to room temperature, the light brown reaction solution was treated with pentane to precipitate the product as a beige powder, which was washed with pentane and 
purified by column chromatography (silica gel, $\mathrm{CH}_{2} \mathrm{Cl}_{2} /$ ethyl acetate $60: 1$ ) to give $13 \mathrm{a}(60 \mathrm{mg} .30 \%)$ or $13 \mathrm{~b}(120 \mathrm{mg} .60 \%)$

14: Triketone $13(16.0 \mathrm{mg}, 38.6 \mu \mathrm{mol})$ was heated with $5 \mathrm{~mL}$ of diethylene glycol, $1 \mathrm{~mL}$ of hydrazine hydrate, and $50 \mathrm{mg}$ of $\mathrm{KOH}$ at $140^{\circ} \mathrm{C}$ for $3 \mathrm{~h}$ and then at $210^{\circ} \mathrm{C}$ for $4 \mathrm{~h}$. The reaction mixture was allowed to cool, $5 \mathrm{~mL}$ of water was added, and the mixture was extracted with $\mathrm{CHCl}_{3}(2 \times 10 \mathrm{~mL})$. Filtration through silica gel $\left(\mathrm{CHCl}_{3}\right)$ gave $14(3.0 \mathrm{mg}, 21 \%)$.

Received: January 26, 1994 [Z 6645IE] German version: Angew. Chem. 1994, 106. 1326

[1] P. Gund. T. M. Gund, J. Am. Chem. Soc. 1981, 103, 4458-4465.

[2] Topologically nonplanar means nonplanar according to graph theory. a) D. M. Walba. Tetrahedron 1985, 41, 3161-3212; b) F. Harary in Chemical Applications of Graph Theory (Ed.: A. T. Balaban), Academic Press, London. 1976. Chapter 2: c) I. Simon in Graph Theory and Topology in Chemistry (Eds. R. B. King. D. H. Rouvray), Elsevier, Amsterdam, 1987, p. 43.

[3] a) $O$. Ermer, Aspekte von Krafteldrechnungen, Wolfgang Baur, München. 1981. Chapter 4.6.3: b) W. Luef. R. Keese, Helv. Chim. Acta 1987, 70,543-553.

[4] L. A. Paquette, R. A. Snow, J. L. Muthard, T. Cynkowski, J. Am. Chem. Soe. 1978, $100,1600-1602$

[5] a) D. Kuck, A. Schuster. Ange'u. Chem. 1988, 100, 1222-1224; Angen. Chem Iml. Ed. Eng/. 1988, 27. 1192-1194; b) D. Kuck, A. Schuster, B. Paisdor, D. Gestmann, unpublished

[6] R. Eekrich. D. Kuck, Sinleti 1993, 4, 344-347.

[7] a) D. Kuck. A. Schuster, R. A. Krause. J. Org. Chem. 1991. 56, 3472-3475 b) D. Kuck. A. Schuster. D. Gestmann. J. Chem. Soc. Chem. Commun. 1994. $609-610$

[8] a) H. E. Simmons 11I, J. E. Maggio, Tetrahedron Lett. 1981, 22, 287-290; b) H. E Simmons III, PhD Thesis, Harvard University, 1980; c) S. A. Benner. J. E. Maggio. H. E. Simmons III, J. Am. Chem. Soc. 1981, 103, 1581-1582; d) J. E. Maggio, H. E. Simmons III, ibid. 1981. 103, 1579-1581.

[9] a) L. A. Paquette. M. Vazeux, Tetrahedron Lett. 1981. 22, $291 \ldots 294$; b) L. A Paquette. R. V. Williams, M. Vazeux, A. R. Browne, J. Org. Chem. 1984, 49 2194-2197.

[10] B. Paisdor. D. Kuck, J. Org. Chem. 1991, 56, 4753-4759.

[11] We recently developed a third synthesis of 9 ; see ref. $[5 b, 7 b]$.

[12] Three equivalents of 2 -(trimethylsilyl)vinylmagnesium bromide add to triketone 6 in good yield; attempts to cyclize the resulting triptindantriol were not successful. B. Paisdor, Dissertation, Universität Bielefeld, 1989

[13] All attempts at the oxidative removal of several benzene rings from 9 with the goal of the conversion $\mathbf{9} \rightarrow \mathbf{2}$ (or $\mathbf{3}$ ) have failed so far; see ref. [5b]

[14] For similar intramolecular additions see: J. S. Swenton. A. Callinan. S. Wang, J. Org. Chem. 1992, 57, 78-85.

[15] a) P. A. Grieco, Aldrichimica Acta 1991, 24,59-66; b) P. A. Grieco, J. D. Clark. C. T. Jagoe, J. Am. Chem. Soc. 1991, 113, 5488-5489.

$[16]$ a) Examples of the thermal rearrangement of enol ethers into ketones: $S$. Wang, G. W. Morrow, I. S. Swenton, J. Org. Chem. 1989, 54, 5364-5371, and references therein; b) $\beta$-phenyl substitution of the enol ethers facilitates the $[1,3]$ rearrangement, see ref. [16a].

[17] The marked upfield shift of the three ortho protons of the triptindan framework of $13 \mathrm{~b}$ (to $\delta=6.34$ ) besides that of six ortho protons of the phenyl groups (to $\delta=6.50$ ) provides unequivocal proof of their "exo" orientation relative to the perhydrotriquinacene unit.

[18] Centrosubstituted triquinacenes: a) A. K. Gupta, G. S. Lannoye. G. Kubiak I. Schkeryantz, S. Wehrli, J. M. Cook, J. Am. Chem. Sor. 1989, 111, 2169-2179 b) A. K. Guptat, U. Weiss, J. M. Cook, Fetrahedon Lett. 1988, 29, 2535-2538 c) X. Fu. J. M. Cook. J. Org. Chem. 1992, 57, 5121-5128; d) X. Fu, J. M. Cook, Fetrathedren Lit1. 1990, 31,3409-3412; e) B. Bengtson, Dissertation. Universität Hamburg. 1986; f) see also ref. [6]: g) X. Fu, J. M. Cook, Aldrichimica Acia 1992, 25, 43-54.

[19] Centrosubstituted tribenzotriquinacenes: a) A. Schuster, D. Kuck, Angew Chem. 1991, 103, 1717-1720; Angew'. Chem. Int. Ed. Engl. 1991, 30, 1699 1702 ; b) D Kuck. T. Lindenthal, A. Schuster. Chem. Ber. 1992, 125, 1449 1460. and references therein.

[20] a) D. M. Müller, Chem. Weekbl. 1963,59,334; b) R. B. Woodward. T. Fukunaga, R. C. Kelly, J. Am. Chem. Soc. 1964,86,3162-3164; c) I. T. Jacobsen, Acta Chem. Scand. 1967, 21, 2235-2246.

[21] E. Carceller, M. L. García, A. Moyano, M. A. Pericàs, F. Serratosa, Tetrahe dron 1986, 42,1831-1839.

[22] Reviews: a) Cage Hydrocarbons (Ed.: G. A. Olah), Wiley, New York, 1990 b) L. A. Paquette in [22a]. Chapter 9, pp. 331-335; c) W. D. Fessner, H Prinzbach in [22a]. Chapter 10, pp. 355-357; d) L. A. Paquette, Chem. Rev. 1989. 89, 1051-1065; e) P. E. Eaton, Tetrahedron 1979, 35, 2189-2223.

[23] M. M. Midland, J. Org. Chem. 1975, 40, 2250-2252.

\section{Base-Free Monomeric Organogallium Hydrides **}

Alan H. Cowley, * François P. Gabbaï, Harold S. Isom, Carl J. Carrano, and Marcus R. Bond

Information on neutral gallium mono- and dihydrides is quite sparse. ${ }^{[1]}$ Structurally characterized examples of such species are confined to the dimers $\left[\mathrm{Me}_{2} \mathrm{Ga}(\mu-\mathrm{H})\right]_{2},{ }^{[2]}\left[\mathrm{H}_{2} \mathrm{Ga}(\mu-\mathrm{Cl})\right]_{2},{ }^{[3]}$ $\left[\mathrm{H}_{2} \mathrm{Ga}\left(\mu-\mathrm{NMe}_{2}\right)\right]_{2},{ }^{[4]}$ and $\left[\mathrm{H}_{2} \mathrm{Ga}(\mu-\mathrm{H})_{2} \mathrm{BH}_{2}\right]^{[5]}$ and the novel monomer $\left[\mathrm{HGa}\left(\mathrm{BH}_{4}\right)_{2}\right]$ with a pentacoordinate gallium atom. ${ }^{[6,7]}$ However, the recent detection of the tricoordinate monomers $\mathrm{GaHCl}_{2}$ and $\mathrm{GaH}_{2} \mathrm{Cl}$ in argon matrices ${ }^{[81}$ suggested that monomeric organogallium hydrides might become isolable if sufficiently bulky substituents were employed.

Treatment of $\left[\mathrm{Ga}(\mathrm{Ar}) \mathrm{Cl}_{2}\right]^{[9]}$ $\left(\mathrm{Ar}=2,4,6-t \mathrm{Bu}_{3} \mathrm{C}_{6} \mathrm{H}_{2}\right)$ with $\mathrm{Li}$ $\mathrm{GaH}_{4}$ in $\mathrm{Et}_{2} \mathrm{O}$ at $-78^{\circ} \mathrm{C}$ afforded a $73 \%$ yield of colorless crystalline 1. In the CI mass spectrum of 1 the base peak appears at $m / z 315$ and corresponds to $[\mathrm{Ga}(\mathrm{Ar}) \mathrm{H}]^{+}$. This assignment was confirmed by a high-resolution mass spectrum

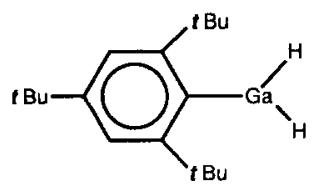

1 (HRMS)..$^{[0]}$ The detection of a terminal $\mathrm{GaH}_{2}$ moiety in the neutral molecule was evident from the presence of infrared peaks in the terminal $\mathrm{Ga}-\mathrm{H}$ stretching region $\left(v_{\mathrm{s}}=1908 \mathrm{~cm}^{-1}(\mathrm{sh}), v_{\mathrm{as}}=1887 \mathrm{~cm}^{-1}\right)$ and the relative intensities of the $\mathrm{GaH}_{2}$ resonance and those of the aryl substituent in the ${ }^{1} \mathrm{H}$ NMR spectrum. ${ }^{[10]}$ Moreover, the deshielded position of the $\mathrm{GaH}_{2}$ resonance $(\delta=6.41)$ was suggestive of a base-free product since, for example, amine-gallane adducts exhibit hydride resonances in the range $\delta=4.5-5.0 .^{[1]}$ The monomeric nature of $\mathbf{1}$ was confirmed by an X-ray structure analysis. ${ }^{[12]}$ Individual molecules of 1 (Fig. 1) reside on a crys-

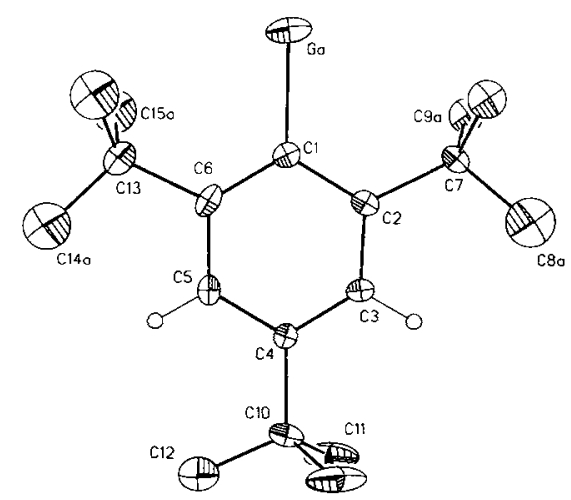

Fig. 1. View of 1 showing the atom labeling scheme. The $t \mathrm{Bu}$ groups at $\mathrm{C} 2$ and $\mathrm{C} 6$ are disordered and only the two highest occupancy methyl carbon atoms are shown. The hydrogen atoms on the gallium atom were not located. Selected distances $[\AA]$ :

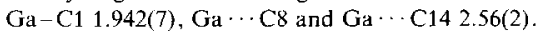

[*] Prof. A. H. Cowley, F. P. Gabbai, H. S. Isom

Department of Chemistry \& Biochemistry

The University of Texas at Austin

Austin, TX 78712 (USA)

Telefax: Int. code + (512)471-6822

Prof. C. J. Carrano, Dr. M. R. Bond

Department of Chemistry

Southwest Texas State University

San Marcos. TX 78666 (USA)

Telefax : Int. code + (512) 245-2374

[**] This work was supported by the National Science Foundation and the Robert A. Welch Foundation. 